\title{
Aborto y derechos humanos
}

\author{
Alejandra Zúñiga Fajuri*
}

\begin{abstract}
RESUMEN
El siguiente trabajo tiene como primer objetivo analizar las condiciones bajo las cuales la restricción de los derechos humanos de las mujeres, en materia reproductiva, resulta coherente con la teoría general de los derechos humanos. En la misma línea se examina si es posible reconocer en el feto algún interés jurídicamente protegible que admita la limitación de los derechos de las mujeres, en atención a sus distintas etapas de desarrollo. Finalmente, se pasa revista brevemente a la polémica relativa a la compatibilidad de una ley que despenalice el aborto con la Constitución chilena.
\end{abstract}

Aborto - derechos humanos - Constitución

\section{Abortion and buman rights}

\begin{abstract}
This paper analyze the conditions under which the restriction of women's human rights it is consistent with general theory of human rights. Next, examined if it's possible recognize a legally protected interest in the fetus that supports limiting women's rights, in relation with fetus different stages of development. Finally, it briefly reviews the controversy regarding the compatibility of a law to decriminalize abortion with Chilean Constitution.
\end{abstract}

Abortion - human rights - constitution

* Abogada, Doctora en derecho, Profesora e investigadora de la Universidad de Valparaíso y la Universidad Diego Portales. Santiago, Chile. E-mail: alejandra.zuniga@uv.cl

Artículo recibido el 29 de julio de 2011 y aceptado para su publicación por el Comité Editorial el 28 de octubre de 2011. 


\section{INTRODUCCIÓN}

$\mathrm{L}$ a Organización Mundial de la Salud, la Comisión Interamericana de Derechos Humanos, la Corte Europea de Derechos Humanos, Amnistía Internacional, Human Rights Watch, el Comité de la ONU contra la Tortura, entre otros, han declarado unánimemente, en los últimos años, que la penalización del aborto cuando la vida o salud de la madre corren peligro o cuando el embarazo es producto de una violación, constituye un acto de tortura que viola los derechos humanos básicos de las mujeres ${ }^{1}$.

¿Qué concepción de los derechos humanos está detrás de esta significativa declaración?

Los derechos humanos, según se ha defendido por la teoría y filosofía política desde, al menos, el siglo XVIII, son derechos subjetivos que reconocen a su titular prerrogativas que sólo pueden ser limitadas con el fin de proteger otros derechos humanos detentados por personas humanas. Ello acarrea, entonces, al menos dos importantes consecuencias: que los derechos humanos no pueden restringirse o anularse con el fin de salvaguardar intereses colectivos, utilitarios o consecuencialistas, tampoco valores sustentados por grupos religiosos o ideológicos, aun cuando ellos sean mayoritarios. En segundo lugar, implica que, para decidir sobre la legitimidad moral y legalidad del aborto, debemos ser capaces de identificar, en contraposición con los derechos humanos de las mujeres, un derecho del embrión o feto en tanto persona o, si esto no es posible, al menos como ente independiente con algún interés jurídicamente protegible.

En las líneas que siguen me ocuparé de analizar el modo en que la penalización absoluta del aborto viola los derechos humanos básicos de las mujeres e intentaré responder a la pregunta sobre si es posible reconocer, en alguna etapa de desarrollo del feto, un derecho o interés que pueda servir de base para justificar restricciones o limitaciones a los derechos humanos de las mujeres, teniendo presente que -como sostenía John Rawlslos derechos sólo pueden restringirse por mor de los propios derechos ${ }^{2}$.

\section{JUSTICIA Distributiva SANitARIA Y MORALIDAD DEL ABORTO}

Cada día mueren 1.500 mujeres por problemas asociados al embarazo o al parto, lo que significa que cada minuto fallece una mujer a causa de su embarazo. Las muertes maternas están estancadas desde hace 20 años, con más de 500.000 al año. La mortalidad materna es la principal causa de muerte entre mujeres en edad fértil en los países en

${ }^{1}$ El Comité contra la Tortura destacó la incompatibilidad de la penalización total del aborto con la Convención contra la Tortura y Otros Tratos o Penas Crueles Inhumanos y Degradantes, por lo que demandó flexibilidad en el tratamiento legal del aborto terapéutico y en los abortos producidos por causa de violación o incesto. Véase, Comité contra la Tortura de Naciones Unidas. Informe emanado por el Comité reunido en su $42^{\circ}$ periodo de sesiones en la ciudad de Ginebra y en el marco de las observaciones finales del Informe presentado por Nicaragua. Junio de 2009.

${ }^{2}$ Rawls, John, A Theory of justice, Harvard University Press. 1971, p. 204. 
desarrollo y la inmensa mayoría de estas muertes son evitables, lo que evidencia que se trata de "la mayor desigualdad del mundo en materia sanitaria"3.

Las causas de estas muertes siguen siendo las mismas: hemorragias postparto, infecciones, parto prolongado y, como sabemos, los abortos clandestinos que constituyen un $30 \%$ de la tasa anual de mortalidad materna. Ello resulta especialmente alarmante si se tiene en cuenta que se trata de uno de los factores más fáciles de eliminar si se promueve la planificación familiar, se despenaliza la interrupción voluntaria de la gestación y se democratiza el acceso al cuidado sanitario. Cerca de 200 mujeres mueren al día en todo el mundo al someterse a un aborto sin las mínimas condiciones de higiene ${ }^{4}$. La tendencia a la baja en el número de hijos por mujer, que se constata en casi todo el planeta salvo en África subsahariana ${ }^{5}$, no ha evitado que aún hoy cerca del $50 \%$ de los embarazos sean no deseados, por lo que cada año se practican 20 millones de abortos en condiciones insalubres, con métodos peligrosos o autoinducidos. Ello significa que este año unas 80.000 mujeres morirán a consecuencia de este tipo de abortos. Además, más de cinco millones ingresarán en un hospital, quedarán estériles o sufrirán alteraciones durante el resto de su vida ${ }^{6}$ (aproximadamente 800.000 latinoamericanas son hospitalizadas anualmente debido a estas complicaciones) ${ }^{7}$.

Sostener la ilegalidad del aborto es una forma sumamente costosa, en vidas humanas, de distribuir los escasos recursos médicos. "La pregunta no es si estamos de acuerdo o no con el aborto porque, ya sea legal o no, las mujeres se practican abortos como lo demuestran las estadísticas. Por el contrario, la alternativa es escoger entre la vida y la muerte de estas mujeres. Actualmente, mantener las leyes penalizantes vigentes significa

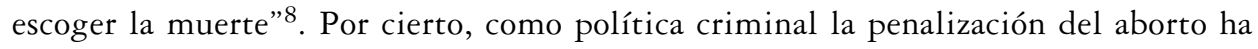
demostrado ser extraordinariamente ineficaz. Hacer que el aborto sea ilegal no reduce el número de abortos pues, sólo en América del Sur, aproximadamente 30 de cada 1.000 mujeres (de entre 15 y 45 años) se hacen un aborto por año. En Holanda, donde el aborto es legal, la cifra es 8 de cada 1.000. Penalizarlo sólo discrimina a las mujeres sin recursos, pues donde el aborto es legal el riesgo de muerte es menor de 1 por cada 500.000 mujeres. Esto significa que un aborto legal es más seguro que ningún otro tipo de procedimiento médico y que tiene un menor riesgo de muerte que un tratamiento con penicilina.

${ }^{3}$ UNICEF. State of the World's Children, Informe del año 2011.

${ }^{4}$ United Nations Population Fund. Making reproductive rights and sexual and reproductive health reproductive rights and sexual and reproductive health a reality for all. UNPF. Mayo, 2008.

${ }^{5}$ Donde se calcula que entre 1990 y 2015 la fertilidad aumentará un 43\%. Organización Mundial de la Salud. Revised 1990 estimates of maternal mortality: A new approach by WHO and UNICEF. Ginebra, OMS. 1996.

${ }^{6}$ Organización Mundial de la Salud. Unsafe abortion: Global and regional estimates of incidence of unsafe abortion and associated mortality in 2000. 4a. edición. Ginebra, OMS. 2004.

${ }^{7}$ Childbirth by Choice Trust, Abortion in Law, History and Religion, Toronto, 1995, p. 39.

${ }^{8}$ De la Barreda Solórzano, El delito de aborto, una careta de buena conciencia. Instituto Nacional de Estudios Criminales, México, 1991. 
Por otro lado, dar a luz es uno de los eventos más peligrosos en la vida de una mujer. En Europa una de cada 10.000 mujeres muere en el parto. Dar a luz es mucho más peligroso que un aborto seguro, de modo que no hay motivos aceptables para que una mujer de escasos recursos muera, enferme o quede infértil como resultado de un aborto clandestino. En Chile los abortos inseguros son la tercera causa de muerte materna y, al igual que las víctimas de las sanciones penales derivadas, son un peligro sólo para quienes no pueden financiarse, en el sistema sanitario privado, una interrupción del embarazo sin riegos9. En fin, vale la pena recordar que el aborto está absolutamente prohibido en todas las circunstancias sólo en cuatro países en el mundo: Nicaragua, República Dominicana, El Salvador y Chile ${ }^{10}$.

\section{Aborto y derechos humanos}

Una primera aproximación a la noción de "derechos humanos" requiere analizar las dos unidades semánticas que la componen. Por una parte, la palabra "derecho" -que admite al menos tres sentidos- se utiliza en este caso para aludir a alguna forma de facultad o potestad que le asiste a una persona; y, por otro lado, la palabra "humanos" se refiere a la única propiedad relevante para ser titular de estos derechos. Esta formulación, aparentemente simple, ya tiene dos grandes dificultades asociadas a cada una de las palabras escindidas: una, qué hace que una persona humana sea tal y, dos, qué significa tener un derecho ${ }^{11}$.

Usualmente se defiende que los derechos humanos presentan las siguientes características analíticas, en el sentido de que se presuponen en el concepto ${ }^{12}$ :

a) Son intrínsecos. Esto quiere decir que su posesión no depende de ninguna otra característica que el hecho de ser persona humana;

b) Son universales, pues se trata de derechos de los cuales son titulares todos quienes sean personas humanas, sin excepción;

${ }^{9}$ Perfil de Salud de Mujeres y Hombres en Chile 2003. Organización Panamericana de la Salud/Organización Mundial de la Salud. 2003.

${ }^{10}$ No está de más anotar aquí que la legislación chilena posee escaso apoyo popular. Así, según muestran los estudios, el $75 \%$ de las mujeres está de acuerdo con el aborto si se trata de salvar la vida de la madre; el $71 \%$ si hubo violación y el $68 \%$ cuando el feto tiene una malformación grave. En Mujer y Política 2006, Corporación Humanas e Instituto de Asuntos Públicos de la Universidad de Chile. 2007.

${ }^{11}$ Nino, Carlos, Ética y Derechos Humanos, Astrea, Buenos Aires, 1989 y del mismo autor, "Los Titulares de los Derechos Humanos: El Concepto de Persona Moral", en Filosofía del Lenguaje, de la Ciencia, de los Derechos Humanos y Problemas de su Enseñanza, Sociedad Filosófica Iberoamericana, Universidad Autónoma de México, 1987. También, Villavicencio, Luis, ¿Derechos humanos para quiénes? Reflexiones sobre algunas cuestiones embarazosas". En Revista de Derecho de la Universidad Austral de Chile, volumen XXI, N², 2008, pp. 35-36.

${ }^{12}$ Véase De Lora, Pablo, Memorias y frontera, el desafío de los derechos humanos. Alianza, Madrid, 2006; Laporta, Francisco, "El concepto de derechos humanos". Doxa N 4, 1987; Peña, Carlos, "Sobre el Concepto y el Fundamento de los Derechos Humanos". Cuadernos de Análisis Jurídico, $\mathrm{N}^{\circ} 27$, Universidad Diego Portales, Santiago, 1993 y Villavicencio, Luis, La Constitución y los Derechos Humanos, Conosur, Santiago, 1998. 
c) Son igualitarios, lo que quiere decir que todos los seres humanos poseen un título igual a tales derechos, puesto que todos tienen, en idéntica medida, el único requisito que es necesario para tenerlos: ser persona humana.

d) Son prioritarios o absolutos. Esto quiere decir que los derechos humanos son exigencias morales fuertes y esa fuerza descansa en que son la concreción de bienes de particular relevancia para los seres humanos. Más específicamente, cuando se sostiene que los derechos humanos son derechos absolutos lo que queremos decir es, precisamente, que se trata de requerimientos morales que, al entrar en conflicto con otros requerimientos morales, los desplazan y anulan, quedando ellos como la exigencia moral que hay que satisfacer en todo caso" 13 .

En este sentido se afirma que los derechos humanos tienen un carácter "prima facie', en principio no pueden ser vulnerados y sólo pueden verse limitados por los derechos de otras personas. "Lo importante, para una teoría ética basada en los derechos humanos es determinar las razones por las que podríamos, en esos supuestos, sacrificar los derechos; especificar las circunstancias que nos permitan acabar con los bienes más importantes de la persona" 14 .

e) Son individualizados y no agregativos. Esto es, ningún ente que no sea un ser humano individualmente considerado detenta tales derechos, por lo tanto, ni la mayoría, ni el Estado, ni el bien común o cualquier otra denominación similar, tienen derechos concurrentes que puedan justificar moralmente su violación o excepción y podemos incluir aquí, ni valores de tipo religioso o metafísico como el "sagrado valor de la vida humana".

Si bien hay autores que sostienen que, además, los derechos humanos son inalienables o irrenunciables, la mayoría de los teóricos políticos rechaza este concepto por su carácter paternalista y, en cierto modo, autoritario, pues sostener la irrenunciabilidad de un derecho lo transformaría, por definición, en un 'derecho-deber', lo que es un contrasentido que no se justifica moralmente. Por lo mismo, esta tesis -que cae en la contradicción derivada de suponer que los derechos humanos son irrenunciables hasta por sus propios titulares- puede superarse siguiendo a Laporta, quien distingue entre la 'titularidad' de los derechos y su 'ejercicio'. En general, la titularidad de los derechos humanos sería inalienable, pero su ejercicio puede ser voluntariamente limitado por el propio titular ${ }^{15}$.

f) Son contramayoritarios o derechos fuertes, pues se comportan como límite o umbral, una "carta de triunfo" en contra de medidas fundadas en la consecución de objetivos sociales colectivos ${ }^{16}$. Si un derecho cediera cada vez que se demostrase que su ignorancia conduce a una situación socialmente valiosa, no sería un genuino derecho sino una concesión precaria que sólo se hace en vista del interés

\footnotetext{
${ }^{13}$ Laporta, Francisco, "El concepto de derechos humanos". Doxa N 4, 1987, p. 39.

${ }^{14}$ De Lora, Pablo, Memorias y frontera, el desafío de los derechos humanos. Alianza, Madrid, 2006, p. 120.

${ }^{15}$ Ibid., Laporta, 1987, p. 44.

${ }^{16}$ Dworkin, Ronald, Los Derechos en Serio, Ariel, Barcelona, 1989, pp. 158 a 162.
} 
colectivo. Entonces, los derechos humanos son derechos fuertes en el sentido que no admiten restricciones justificadas en la consecución de objetivos sociales o colectivos, aunque sean deseables de alcanzar ${ }^{17}$.

En conclusión, considerar "en serio" los derechos humanos de las mujeres exige aceptar que se trata de derechos que sólo pueden ser limitados con el fin de proteger otros derechos humanos individualmente detentados por otra persona, de modo que resulta forzoso descartar como ilegítimos los fundamentos que distintas legislaciones y tribunales han esgrimido para justificar la penalización del aborto: la protección del "valor abstracto de la vida humana" ${ }^{18}$. En cambio, la única manera legítima-acorde con el concepto y características de los derechos humanos que se ha apuntado- de limitar los derechos de las mujeres requiere partir de los siguientes supuestos: primero, se precisa analizar si el feto posee las características que usualmente atribuimos a las personas, únicas titulares de derechos. Segundo, de no ser posible lo anterior, debemos analizar si es factible que, a partir de cierto momento de su desarrollo, el feto desarrolle particularidades que ameriten que le atribuyamos derechos.

¿Significa lo anterior que la única manera de limitar legítimamente los derechos humanos de las mujeres en materia reproductiva sería aceptando que el feto es una persona? Para algunos ni siquiera así sería posible. El clásico argumento, desarrollado por J.J. Thomson, que defiende la idea de que, aun considerando al feto como persona, la madre tendría, en ciertas circunstancias, el legítimo derecho de abortar, es el siguiente:

\begin{abstract}
"Permítanme pedirles que se imaginen que una mañana despiertan en la cama de un hospital, conectados de alguna manera a un hombre inconsciente que se encuentra en la cama contigua. Le dicen que ese hombre es un violinista famoso que tiene una enfermedad renal y su única forma de sobrevivir es manteniendo su sistema circulatorio conectado al de otro individuo con el mismo grupo sanguíneo y usted es la única persona con la sangre adecuada. Así, una asociación de amantes de la música le ha secuestrado y llevado a cabo la operación de conexión. Como se encuentra en un hospital de buena reputación podría, si quisiera, solicitar a un médico que le desconectara del violinista, en cuyo caso él moriría irremediablemente. Por otra parte, si permanece conectado durante 'sólo' nueve meses, el violinista se recuperaría y podría luego usted ser desconectado sin poner en peligro su vida” ${ }^{19}$.
\end{abstract}

La autora considera que si nos viéramos inmersos en esta situación inesperada, no estaríamos moralmente obligados a permitir que el violinista utilizara nuestros riñones durante nueve meses. Ayudar al violinista sería, claro, un acto muy generoso de nuestra

${ }^{17}$ Nino, Carlos, Ética y Derechos Humanos. Editorial Paidós. Buenos Aires. 1984.

18 Véase, por ejemplo, Tribunal Constitucional Español, sentencia 53/1985, de 11 de abril de 1985; Corte Constitucional Alemana, sentencia del 25 de febrero de 1975, 39 BVerfGE 1; Corte Constitucional de Colombia, sentencia C-133, de 1994.

19 Thomson, J.J., "Una defensa del aborto", en Debate sobre el aborto, cinco ensayos de filosofía moral, Cátedra, Madrid, 1992. 
parte, pero decir esto es bastante distinto de decir que haríamos mal si actuáramos de otra manera y nos desconectáramos. La conclusión, por tanto, es que, aun considerando que el violinista sea un ser humano inocente, con el mismo derecho a la vida que el de cualquiera, ello no significa que pueda utilizar el cuerpo de otra persona para sobrevivir. La idea es mostrar el paralelismo de este caso hipotético con algunos casos de embarazos no deseados. Por ejemplo, resulta evidente que una mujer que ha quedado embarazada como resultado de una violación se encontraría a sí misma, de un momento a otro, 'conectada' a un feto del que no es, de manera alguna, más responsable que lo que lo sería de la vida del violinista.

Con todo, por muy interesante que parezca el ejercicio filosófico-jurídico ideado por Thomson, lo cierto es que existen serias dificultades para considerar al feto como 'persona'. En esta línea, debemos acordar algún concepto de persona que sintetice las dos nociones que suelen superponerse, la de persona legal y la de persona moral. Sobre el concepto de persona legal no hay gran discusión pues tanto la legislación nacional como la comparada expresan que sólo quienes han nacido son, técnicamente, 'personas' para los efectos de la titularidad de derechos subjetivos. En particular, nuestra legislación es suficientemente clara sobre el particular puesto que ya el Código Civil, en el Título II relativo al "principio y fin de la existencia de las personas naturales" dispone en el artículo 74 "La existencia legal de toda persona principia al nacer, esto es, al separarse completamente de la madre”. En coherencia con lo anterior, según veremos, la Constitución da un tratamiento distinto del de las personas al que está por nacer (en el artículo $19 \mathrm{~N}^{\circ} 1$ inciso 2) y el Código Penal establece para el aborto una pena inferior al infanticidio y al parricidio, regulando el aborto en una sección, de nuevo, diferente de aquella referida a los "delitos contra las personas" ${ }^{20}$.

¿Sin embargo, es el feto una persona moral? El concepto de persona moral, propio de la filosofía política, ha sido especialmente desarrollado por John Rawls en base a la teoría de Kant sobre el actuar autónomo, el actuar ético. Desde este punto de vista los requisitos para ser considerados persona son más estrictos que el solo hecho de haber nacido. Las personas morales, sostiene Rawls, son aquellas capaces de detentar dos virtudes morales: por una parte, un sentido de la justicia y, por la otra, una cierta concepción del bien. El primero exige la capacidad de entender, aplicar y actuar según la concepción pública de la justicia que caracteriza a los términos equitativos de la cooperación social. La segunda, la capacidad de adoptar una cierta concepción del bien, esto es, "una familia ordenada de fines y objetivos últimos que definen la concepción que tiene la persona de lo que tiene valor en la vida humana" ${ }^{21}$. Y concluye que "sólo los que pueden hacer justicia tienen derecho a la justicia" 22 de modo que no parece posible considerar al feto

${ }^{20}$ Para un buen análisis del concepto 'legal' de persona, véase Figueroa, Rodolfo, "Concepto de persona, titularidad del derecho a la vida y aborto". Revista de Derecho de la Universidad Austral de Chile. Vol. XX, $\mathrm{N}^{\circ}$ 2. 2007. También, Bascuñán Rodríguez, "La licitud del aborto consentido en el Derecho chileno", en Derecho y Humanidades, $\mathrm{N}^{\circ}$ 10, Universidad de Chile, Santiago. 2004.

${ }^{21}$ Rawls, John, La Justicia como equidad. Una reformulación, Paidós, Barcelona. 2002, p. 43.

${ }^{22}$ Rawls, John, A Theory of justice, Harvard University Press. 1971, p. 510. 
como persona moral puesto que ni siquiera un recién nacido sería capaz de responder a la noción de persona desarrollada a partir del ideal kantiano de autonomía moral ${ }^{23}$.

¿Qué importancia tiene lo anterior para la regulación del aborto? Desde ya parece ineludible aceptar que, puesto que no hay 'otra persona' - sea legal o moral- que pueda oponer sus derechos a los de la mujer, no habría justificación alguna para limitar o excluir sus derechos humanos los que, además, poseen el carácter de prioritarios o absolutos -sólo pueden verse limitados en caso de conflicto con los derechos de otras personas-, son individualizados -ningún ente o valor que no sea una persona humana individualmente considerada detenta tales derechos-y son contramayoritarios - derechos fuertes, 'cartas de triunfo' en contra de intereses colectivos-.

Ello, sin embargo, no significa que no podamos encontrar argumentos que permitan regular e incluso restringir el derecho al aborto, pero debemos hacerlo demostrando cómo es posible identificar en el feto, individualmente considerado, y en atención a sus distintas etapas de su desarrollo, ciertas características compartidas con las personas, que ameriten que le atribuyamos derechos por sí mismo. Se requiere identificar cuándo el propio feto adquiere un interés relevante digno de ser protegido y capaz de desplazar el derecho fundamental de la mujer a la autonomía reproductiva. Aquí hay dos caminos posibles, primero, atender a la capacidad del feto de sentir dolor o de ser consciente de sufrimiento y, segundo, prestar atención al momento de la viabilidad fetal, esto es, a la capacidad del feto de vivir fuera del útero materno.

Empecemos por el segundo argumento. El problema asociado a la tesis de la viabilidad -utilizada, como se sabe, por la Corte Suprema estadounidense para despenalizar el aborto ya en el año $1973^{24}$ - está en que debido al rápido desarrollo de la ciencia, el plazo de la viabilidad -que hoy ronda en las 24 semanas de gestación- podría ir variando obligándonos a restringir cada vez más los derechos de las mujeres. Por ello, parece preferible argumentar en torno a si es posible que el feto posea algún interés independiente jurídicamente protegible, sustentado teóricamente en la convicción de que no es lo mismo un aborto temprano que uno tardío, tesis que ha venido a validar las reformas legislativas de varios países en Europa ${ }^{25}$. En palabras de Valdés “las obligaciones

${ }^{23}$ Sobre las dificultades lógicas derivadas de los conceptos de 'persona biológica' y de 'persona potencial', véase Villavicencio, Luis, ¿Derechos humanos para quienes? Reflexiones sobre algunas cuestiones embarazosas”. En Revista de Derecho de la Universidad Austral de Chile, Vol. XXI, N 2, 2008, pp. 33-51. También, Valdés, Margarita, "El problema del aborto: tres enfoques", en Bioética y Derecho, fundamentos y problemas actuales. Rodolfo Vásquez (ed.), Fondo de Cultura Económica, México, 1999.

${ }^{24}$ Véase, Roe Vs. Wade, 410 U.S. 113 1973. Revisada en Planned Parenthood vs. Casey, 505 U.S. 833. 1992.

${ }^{25}$ En el último tiempo se han reemplazado las 'leyes de indicaciones' por las leyes de plazo' como sistemas de regulación del aborto en Europa. El “sistema de indicaciones”, que permite el aborto en determinadas situaciones, parte del esquema regla-excepción: la regla es el castigo del aborto; la excepción, permitir el aborto en ciertos supuestos expresamente regulados (indicaciones): Las indicaciones más frecuentes son: 1) La terapéutica: Si como consecuencia del embarazo existe un grave peligro para la salud o la vida de la madre; 2) La ética o criminológica: Cuando el embarazo es el resultado de un delito de naturaleza sexual o de la aplicación de una técnica de reproducción asistida no consentida por la madre; 3) La eugenésica: Se aplica cuando se han comprobado serios riesgos de que el feto nazca con graves taras físicas o psíquicas y; 4) $L a$ económico-social: Esta incluye la escasez de recursos económicos de la madre, el elevado número de hijos, el 
morales que se tienen frente a una persona ya nacida no son las mismas que las que se tienen frente a un óvulo fecundado. Por ejemplo, a este último no lo podemos lastimar ya que carece de toda sensibilidad. Tampoco parece como algo cuyos deseos o intereses personales o planes de vida podamos contrariar, porque simplemente no posee ninguno $(\ldots)^{26 "}$. Al parecer, los óvulos fecundados resultan ser distintos de las personas precisamente en aquellos aspectos que importan a la moralidad (dolor, deseos o intereses).

La ciencia ha probado que el desarrollo del ser humano es un proceso gradual. "El óvulo fecundado es una célula individual que, después de unos días, sigue siendo un diminuto conjunto de células sin ningún rasgo anatómico del ser en el que se convertirá posteriormente (...) hasta los 14 días después de la fertilización, ni siquiera podemos saber si el embrión va a ser uno o dos individuos" 27 ¿Es verdad que no existiría ninguna línea divisoria moralmente significativa entre el óvulo fecundado y el niño? Como vimos, las sugeridas normalmente -el nacimiento, la viabilidad y el movimiento- no parecen pertinentes. Sí parece importante, en cambio, la capacidad del feto de sentir dolor o de ser consciente de sufrimiento.

Entonces ¿Tienen los fetos derechos o intereses jurídicamente protegibles en tanto seres individualmente considerados? Si el feto es capaz de sentir dolor, sostiene Singer, entonces "tendría interés en no sentirlo y a ese interés se le debería dar igual consideración que a los intereses similares de cualquier otro ser" ${ }^{28}$. En la misma línea, para Dworkin resulta muy difícil defender la idea que postula que el feto tiene intereses propios, en particular, un interés en no ser destruido desde el momento mismo de la fecundación ${ }^{29}$. Pero, en cambio, sí es posible atribuir interés al feto cuando éste es capaz de sentir dolor. "Infligir dolor al feto, que está dotado de un sistema nervioso suficientemente desarrollado para sentirlo, es también muy desfavorable a sus intereses. Pero un feto no puede ser consciente del dolor hasta el final del embarazo porque hasta entonces su cerebro no está lo suficientemente desarrollado" 30 .

Las últimas investigaciones médicas publicadas en diversas revistas científicas indican que los fetos sólo son capaces de sentir dolor a las 29 o 30 semanas, entre 6 y 7

embarazo fruto de relaciones extramatrimoniales, etc. Por su parte, el "sistema de los plazos" supone que el aborto es completamente libre hasta que se llega a un momento determinado de la gestación que suele fijarse en torno a las doce primeras semanas del embarazo. Hasta que se cumpla dicho plazo, la madre puede decidir con entera libertad sobre la continuación o interrupción del embarazo, con la sola condición de que sea realizada por un médico en un hospital o consultorio que garantice un aborto seguro y, a veces, se suma la exigencia de una consulta previa médico-social de los profesionales correspondientes. A partir del plazo que señala la ley el aborto puede ser lícito siempre que se den alguna de las indicaciones recién vistas. En Romeo Casabona, "El derecho y la bioética ante los límites de la vida humana", Editorial Centro de Estudios Ramón Areces, Madrid, 1994.

26 Valdés, Margarita, "El problema del aborto: tres enfoques", en Bioética y Derecho, fundamentos y problemas actuales, Rodolfo Vásquez (ed.), Fondo de Cultura Económica, México, 1999, pp. 131 y ss.

${ }^{27}$ Peter Singer, Ética práctica, Cambridge University Press, 1995, p. 169.

${ }^{28}$ Ibid., Singer, 1995, p. 203.

${ }^{29}$ Ronald Dworkin, El Dominio de la Vida, Ariel, Barcelona, 1994, p. 19.

${ }^{30}$ Ibid., Dworkin, 1994, p. 27. 
meses de embarazo, puesto que las estructuras cerebrales donde se reconoce un estímulo desagradable son las últimas que se forman durante la gestación. El dolor viaja por el sistema nervioso y en el feto lo último que se forma son las células más especializadas del cerebro, la corteza cerebral. "La percepción del dolor requiere el reconocimiento consciente o conciencia de un estímulo nocivo. Ni los reflejos de retirada, ni las respuestas hormonales de estrés para procedimientos invasivos prueban la existencia de dolor en el feto, ya que pueden ser provocadas por estímulos no dolorosos y producirse sin el procesamiento cortical consciente. La conciencia del feto ante estímulos nocivos requiere conexiones funcionales tálamo-corticales. Las fibras tálamo-corticales comienzan a aparecer entre las 23 a 30 semanas de gestación, mientras que la electro-encefalografía indica que la capacidad de percepción del dolor funcional en los recién nacidos prematuros no existe, probablemente, antes de las 29 o 30 semanas" 31.

Así, por lo demás, ha argumentado el Colegio de Bioética de México durante las discusiones originadas a propósito de la despenalización del aborto en dicho país. "Los conocimientos científicos sobre el genoma, la fertilización, el desarrollo del embrión humano y la fisiología del embarazo indican que el embrión de 12 semanas no es un individuo biológico ni mucho menos una persona, porque:

a) Carece de vida independiente, ya que es totalmente inviable fuera del útero;

b) Si bien posee el genoma humano completo, considerar que por esto el embrión de 12 semanas es persona, obligaría a aceptar como persona a cualquier célula u órgano del organismo adulto, que también tienen el genoma completo. La extirpación de un órgano equivaldría entonces a matar a miles de millones de personas;

c) A las 12 semanas el desarrollo del cerebro está apenas en sus etapas iniciales y no se ha desarrollado la corteza cerebral ni se han establecido las conexiones nerviosas hacia esa región que son indispensables para que puedan existir las sensaciones;

d) Por lo anterior, el embrión de 12 semanas no es capaz de experimentar dolor ni ninguna otra percepción sensorial, y mucho menos de sufrir o de gozar" 32 .

Esta evidencia científica parece haber sido uno de los principales fundamentos de la mayoría de las legislaciones del mundo desarrollado que han transitado desde las leyes de indicaciones a las leyes de plazos, pues parece razonable y coherente con la teoría

${ }^{31}$ Susan J. Lee, Henry J. Peter Ralston, Eleanor A. Drey, John Colin Partridge, Mark A. Rosen, "Fetal Pain. A Systematic Multidisciplinary Review of the Evidence". Journal of the American Medical Association (JAMA). Agosto 24/31, 2005. Vol. 294, No. 8: 947-954. Los resultados de este estudio vienen a corroborar las conclusiones de estudios realizados en las décadas de los 80 y 90 del pasado siglo. Véase; Stuart W. G. Derbyshire y Ann Furedi, "Fetal pain is a misnomer", British Medical Journal, Volume 313:795, September, 1996; Giannakoulopoulos, X., Sepulveda, W., Kourtis, P., Glover, V., Fisk, N.M., "Fetal plasma cortisol and (beta)-endorphin response to intrauterine needling”. Lancet, 1994, Jul 9; 344(8915):73-4; Wall, P., Melzack, R., Fitzgerald, M., "Neurobiology of fetal and neonatal pain”, en: Wall, P., Melzack, R. (eds.). Textbook of pain. Edinburgh: Churchill Livingstone,1994; Fitzgerald, M., Fetal pain: an update of current scientific knowledge. London: DoH, 1995; Mrzljak, L., Uylings, H.B.M., Kostovic, I., van Eden, C.G., "Prenatal development of neurons in prefrontal cortex: a qualitative Golgi study". Journal of comparative neurology, 1988; Vol. 271, 3: 355-386.

32 Informe del Colegio de Bioética de México. En Revista Proceso. Semanario de información y análisis. $\mathrm{N}^{\circ} 1590.22$ de abril de 2007, p. 8. 
de los derechos humanos que he venido analizando que, si la restricción de derechos requiere ser justificada sobre la base del dualismo "persona-persona", las legislaciones que regulen el aborto debieran, luego, limitarlo sólo cuando sea posible reconocer, en el feto mismo, alguna de las características relevantes compartidas por las personas humanas: percepción y conciencia del dolor.

Es por ello que el límite legal para realizar abortos, en la mayoría de los países de Europa, es de 12 semanas. El país donde el límite es mayor es Chipre (con 28 semanas, pero sólo en ciertas circunstancias). Le siguen con 24 semanas Finlandia, el Reino Unido y Holanda. El resto de los países oscila entre las 12 y 22 semanas. En la misma línea, en los Estados Unidos resulta inconstitucional prohibir el aborto durante los dos primeros trimestres de embarazo ${ }^{33}$.

\section{La CONSTitución de i980 y El ABORTo}

¿Es compatible el aborto con nuestra Constitución? Varios trabajos han intentado ya dar respuesta a esta importante pregunta, por lo que aquí no haré más que consignar algunas de las conclusiones a las que, a estas alturas, es posible llegar en la materia ${ }^{34}$.

Por lo pronto, parece que bajo el alero de la Constitución, aplicando las reglas de interpretación de normas y principios, sólo son personas -y por ello titulares de derechos constitucionales- los seres humanos nacidos pues el artículo $19 \mathrm{~N}^{\circ} 1$ de la Constitución ha reservado el inciso primero para el reconocimiento del derecho a la vida de las personas, dejando el inciso segundo para regular la situación del nasciturus, no directamente, sino que ordenando al legislador su protección. O, lo que es lo mismo, delegando -a diferencia de lo que ocurre con el caso de 'las personas'- al legislador la determinación de su estatuto legal y mecanismos de protección.

Por otra parte, nuestro ordenamiento jurídico, tanto en el ámbito civil como penal, considera como estatutos diferenciados aquellos destinados a regular a las personas nacidas y al nasciturus, aclarando en el Código Civil, a propósito del inicio de la existencia legal de las personas, que ellas deben estar nacidas y, a la vez, destinando en el Código Penal penalidades distintas al delito de homicidio y de infanticidio.

En tercer lugar, sin perjuicio de que el mecanismo originalista de interpretación de normas constitucionales no nos parece el más idóneo, es inevitable recordar aquí que la incorporación del mencionado inciso segundo -según consta en las Actas oficiales de la Comisión de Estudio de la Nueva Constitución, Sesión $87^{\mathrm{a}}$ de 14 de noviembre de 1974- tuvo precisamente como objetivo dejar claro que la mayoría de los redactores de la

33 Roe Vs. Wade, 410 U.S. 1131973.

${ }^{34}$ Véase, Ibíd, Figueroa, 2007 y Bascuñán Rodríguez, 2004. De este último autor, también, "El estatuto del embrión preimplantacional: observaciones desde un punto de vista jurídico”, en El embrión bumano, Editorial Mediterráneo, Santiago, 2002. 
Constitución no quiso probibir el aborto en todos los casos sino que, cosa distinta, permitirlo en el supuesto de violación o en el caso de aborto terapéutico ${ }^{35}$.

Finalmente, en cuarto lugar, resulta fundamental recordar que la única resolución que el Sistema Interamericano de Protección de Derechos Humanos habría adoptado en la interpretación del artículo 4 número 1 de la Convención Americana sobre Derechos Humanos, relativo al derecho a la vida, fue la Resolución del año 1981 sobre el llamado caso "Baby Boy", donde se consideró que una interpretación restrictiva de la norma afectaría negativamente a la mayoría de los Estados americanos que permitían el aborto. En otras palabras, la frase "en general" contenida en el artículo $4 \mathrm{~N}^{\circ} 1$ del Pacto de San José de Costa Rica se incorporó con el fin de rechazar, explícitamente, una interpretación que pudiera considerar a las leyes que han despenalizado el aborto en América Latina, como incompatibles con la Convención Americana de Derechos Humanos ${ }^{36}$.

Una interpretación adecuada de los conflictos que emanan de las normas constitucionales que reconocen derechos a las personas -las mujeres- y las normas legales que determinan el estatuto del embrión, debiera ir en la línea de aquel principio kantiano que defiende que los individuos son fines, no medios que puedan ser sacrificados o usados, sin su consentimiento, para alcanzar otros fines, principio que ha tenido un importante reconocimiento en la materia por la Corte Constitucional de Colombia que decidió sobre la inconstitucionalidad requerida contra un artículo del Código Penal que regula el "homicidio por piedad" o eutanásico, distinguiendo dos posiciones posibles: 1) La que asume la vida como algo 'sagrado' y 2) aquella que estima que es un bien valioso pero 'no sagrado', pues las creencias religiosas o las convicciones metafísicas que fundamentan la sacralización son apenas una entre diversas opciones ${ }^{37}$. Para el consti-

35 Véase, Actas de la Comisión de Estudio de la Nueva Constitución, sesión 90 del 25 de noviembre de 1974, pp.19 y ss: El comisionado señor Ovalle sostiene: “personalmente, no sólo es partidario del aborto terapéutico, sino que de otros casos más, que para él se justifican en plenitud, y estima que el legislador, ante el deseo del constituyente de no liberalizar la legislación relativa al aborto, en los términos tan amplios a que se ha referido, tendrá que consignar con un espíritu restrictivo, consciente y muy concreto, los diversos casos que, desde el punto de vista que él tenga, puedan justificar un aborto, y en ese orden de ideas entiende este problema". Por su parte "El señor Ortúzar (Presidente) expresa que no tiene inconveniente en aceptar que se deje constancia en el Acta, de las sugerencias formuladas por el señor Silva Bascuñán y complementadas por el señor Evans, pero en el entendido, también, de que al referirse a esta forma de aborto -el aborto terapéutico- se está señalado la forma principal que, probablemente, podrá considerar el legislador, pero no se atrevería a afirmar que es la única, por las razones señaladas por el señor Ovalle, y porque cree que debe situarse en el caso de que, si el día de mañana ocurriera una violación, incluso una violación masiva de alumnas de una escuela, y que siendo legisladores los miembros de la comisión, tuvieran que entrar a establecer la posibilidad de considerar como lícito, en ese caso, el aborto, declara que en esa situación se encontraría frente a un grave problema de conciencia, porque si le ocurriera en lo personal, con respecto a su hija, tendría el problema de conciencia, y probablemente, si los antecedentes del violador fueren los de un anormal, degenerado o delincuente, etcétera, se inclinaría incluso a autorizar ese caso de aborto”. El único que se opuso al texto acordado por la mayoría de la Comisión fue Jaime Guzmán pues se rechazó su propuesta de prohibir el aborto en todos los supuestos.

${ }^{36}$ Comisión Interamericana de Derechos Humanos. Resolución No 23/81, Caso 2141 contra EEUU, 6 de marzo 1981.

${ }^{37}$ Corte Constitucional de Colombia, Sentencia C-239/97. 
tucional, estos dilemas se deben resolver desde una perspectiva secular y pluralista, que respete la autonomía moral del individuo y las libertades y derechos que inspiran el ordenamiento jurídico, pues las demandas heroicas fundadas en creencias religiosas sólo pueden revestir el carácter de opción, aun cuando "una inmensa mayoría de la población las estime intangibles" 38 .

Se trata, como ya se adivinará, de lo que Rawls denominaba el 'uso publico de la razón', es decir, la eliminación en el debate público de aquellos argumentos propios de doctrinas morales, filosóficas o religiosa 'comprehensivas', que demandan a las autoridades del Estado que justifiquen sus decisiones sobre la base de razones intersubjetivamente válidas, razones que todos los miembros de la comunidad política puedan aceptar ${ }^{39}$. De este modo, para el tribunal, la penalización del aborto en todas las circunstancias implica la completa preeminencia de uno de los bienes jurídicos en juego y el consiguiente sacrificio absoluto de todos los derechos fundamentales de la mujer embarazada, lo que resulta a todas luces inconstitucional puesto que se desconoce su dignidad y se la reduce "a un mero receptáculo de la vida en gestación, carente de derechos o de intereses constitucionalmente relevantes que ameriten protección" 40 . Luego, la mujer "no puede jurídicamente ser obligada a adoptar comportamientos heroicos" ${ }^{41}$ y el legislador no puede desconocer que, como ser humano plenamente digno, no se la puede convertir en un simple instrumento de reproducción de la especie humana.

\section{CONCLUSIÓN}

Quienes argumentan a favor de la penalización del aborto suelen hacerlo en la base a la idea de que las mujeres, una vez que quedan embarazadas, pierden su condición de personas, en el sentido que lo ha entendido Occidente a partir de las grandes revoluciones del siglo XVIII, es decir, individuos dotados de derecho a la libertad, dignidad e igualdad. No se puede dejar de reconocer que el reclamo de las mujeres con un embarazo no deseado es un reclamo asociado a una apelación más amplia por la igualdad de trato. Después de todo ningún otro individuo en ninguna otra situación es obligado a realizar el acto supererogatorio al que son obligadas las mujeres embarazadas.

La teoría general de los derechos humanos demanda coherencia en su aplicación práctica al problema bioético del aborto de modo que resulta imprescindible reconocer

38 Ibid. Sentencia C-239/97.

39 Rawls, John, Justicia como equidad. Tecnos, Madrid. 1999, pp. 132-133.

${ }^{40}$ Sentencia C-355/06. Bogotá, D. C, 10 de mayo de 2006.

${ }^{41}$ La Corte Constitucional de Colombia declara la constitucionalidad de la interrupción del embarazo cuando éste se produzca en las siguientes hipótesis: a) Cuando el embarazo sea producto de acceso carnal o acto sexual sin consentimiento, inseminación artificial o transferencia de óvulo fecundado no consentidas o incesto. En estos casos se requerirá la presentación de la respectiva denuncia ante las autoridades competentes; b) Cuando la vida o la salud física o mental de la madre gestante corran peligro; c) Cuando existan malformaciones del feto que por su gravedad hagan inviable su vida. En las dos últimas hipótesis se requerirá el certificado de un/a profesional de la medicina. Ibid., Sentencia C-355/06. 
que, si la restricción de derechos requiere ser justificada sobre la base del dualismo “persona-persona”, las legislaciones que regulen el aborto podrán restringirlo solo cuando sea posible reconocer, en el nasciturus, alguna de las características relevantes compartidas por las personas humanas, como por ejemplo, la percepción o conciencia del dolor.

Como la evidencia científica de los últimos 30 años ha confirmado que esa característica, que ameritaría una consideración jurídica, solo aparece en la última etapa del embarazo, entonces nuestra legislación debiera no sólo despenalizar el aborto en aquellos casos calificados por las organizaciones de derechos humanos como graves (peligro para la salud y vida de la madre y violación) sino que debiera proponerse, más que una reforma con indicaciones, una ley que, como ha ocurrido en México recientemente, reconozca la importancia de plazos, al momento de dar protección al nasciturus.

\section{BIBLIOGRAFÍA}

BASCUÑÁN RodRíGUEZ, A., "El estatuto del embrión preimplantacional: observaciones desde un punto de vista jurídico", en El embrión humano, Editorial Mediterráneo, Santiago, 2002.

BASCuÑÁn Rodríguez, A., "La licitud del aborto consentido en el Derecho chileno", en Derecho y Humanidades, $\mathrm{N}^{\circ} 10$, Universidad de Chile, Santiago. 2004.

Colegio de Bioética de México. Revista Proceso. Semanario de información y análisis. $\mathrm{N}^{\circ} 1590.22$ de abril de 2007.

Corporación Humanas, Mujer y Política 2006, Corporación Humanas e Instituto de Asuntos Públicos de la Universidad de Chile. 2007.

De la Barreda Solórzano, L., El delito de aborto, una careta de buena conciencia. Instituto Nacional de Estudios Criminales, México, 1991.

De Lora, Pablo, Memorias y frontera, el desafío de los derechos humanos. Alianza, Madrid, 2006.

Dworkin, Ronald, El Dominio de la Vida, Ariel, Barcelona, 1994.

Dworkin, Ronald, Los Derechos en Serio, Ariel, Barcelona, 1989.

Figueroa, Rodolfo, "Concepto de persona, titularidad del derecho a la vida y aborto". Revista de Derecho de la Universidad Austral de Chile. Vol. XX, N². 2007.

FitzGERALD M., Fetal pain: an update of current scientific knowledge. London: DoH, 1995.

Giannakoulopoulos, X., Sepúlveda, W., Kourtis, P., Glover, V., Fisk, N.M., "Fetal plasma cortisol and (beta)-endorphin response to intrauterine needling". Lancet $\mathrm{N}^{\circ} 344,1994$.

Laporta, Francisco, "El concepto de derechos humanos". Doxa N 4, 1987.

Mrzljak L., Uylings HBM, Kostovic I., van Eden C.G., "Prenatal development of neurons in prefrontal cortex: a qualitative Golgi study". Journal of comparative neurology, Vol. 271, 3, 1988.

Nino, Carlos, Ética y Derechos Humanos, Astrea, Buenos Aires, 1989.

Nino, Carlos, "Los Titulares de los Derechos Humanos: El Concepto de Persona Moral”, en Filosofía del Lenguaje, de la Ciencia, de los Derechos Humanos y Problemas de su Enseñanza, Sociedad Filosófica Iberoamericana, Universidad Autónoma de México, 1987.

Organización Mundial de la Salud. Revised 1990 estimates of maternal mortality: A new approach by WHO and UNICEF. Ginebra, OMS. 1996.

Organización Mundial de la Salud. Unsafe abortion: Global and regional estimates of incidence of unsafe abortion and associated mortality in 2000. 4a. edición. Ginebra, OMS. 2004.

Organización Panamericana de la Salud. Perfil de Salud de Mujeres y Hombres en Chile 2003. OPS. 2003. 
Peña, Carlos, "Sobre el Concepto y el Fundamento de los Derechos Humanos". Cuadernos de Análisis Jurídico, N²7, Universidad Diego Portales, Santiago, 1993.

Peter Singer, Ética práctica, Cambridge University Press, 1995.

Rawls, John, A Theory of justice, Harvard University Press. 1971.

Rawls, John, Justicia como equidad. Tecnos, Madrid. 1999.

Rawls, John, La Justicia como equidad. Una reformulación, Paidós, Barcelona. 2002.

Romeo Casabona, C. M., El derecho y la bioética ante los límites de la vida humana, Editorial Centro de Estudios Ramón Areces, Madrid, 1994.

Stuart, W. G., Derbyshire y Ann Furedi, "Fetal pain is a misnomer", British Medical Journal, Volume 313:795, September, 1996.

Susan J. Lee, Henry J. Peter Ralston, Eleanor A. Drey, John Colin Partridge, Mark A. Rosen, "Fetal Pain. A Systematic Multidisciplinary Review of the Evidence". Journal of the American Medical Association (JAMA). Agosto 24/31, 2005. Vol. 294, No. 8.

Thomson, J.J., "Una defensa del aborto", en Debate sobre el aborto, cinco ensayos de filosofía moral, Cátedra, Madrid, 1992.

UNICEF. State of the World's Children, Informe del año 2011.

United Nations Population Fund. Making reproductive rights and sexual and reproductive health reproductive rights and sexual and reproductive health a reality for all. UNPF. Mayo, 2008.

VAldés, MARgarita, "El problema del aborto: tres enfoques”, en Bioética y Derecho, fundamentos y problemas actuales. Rodolfo Vásquez (ed.), Fondo de Cultura Económica, México, 1999.

VILlavicencio, Luis, ¿Derechos humanos para quienes? Reflexiones sobre algunas cuestiones embarazosas". En Revista de Derecho de la Universidad Austral de Chile, volumen XXI, $\mathrm{N}^{\circ} 2,2008$.

Villavicencio, Luis, La Constitución y los Derechos Humanos, Conosur, Santiago, 1998.

Wall, P., Melzack, R., Fitzgerald, M., "Neurobiology of fetal and neonatal pain”, en: Wall, P., Melzack, R. (eds.). Textbook of pain. Edinburgh: Churchill Livingstone, 1994. 
